\title{
Owning Computing's Environmental Impact
}

\section{For decades, we have carried the conceit that "computing makes everything more efficient," so the impact of computing on the environment is a net positive.}

But computing's unprecedented success has produced an explosion in its use, quantity, and direct environmental impact. It is time for the computing community to face up to computing's growing environmental impact-and take responsibility for it! And further, to undertake research, design, and operations to reduce this growing impact. ${ }^{a}$

The transition to SSDs and the consolidation of enterprise computing into efficient cloud datacenters has for a decade blunted the impact of growing computing use. But cloud computing's extraordinary scale $(200 \mathrm{TWh}$, $\$ 200 \mathrm{~B}$ in 2017) and ICT's projected power growth (to $21 \%$ of global power consumption by 2030$)^{5}$ drive the rapid growth of the cloud's atmospheric carbon emissions. ${ }^{3,6}$ Computing is the fastest-growing use of electric power in the developed world, and is driving the buildout of power generation and transmission in much of the developing world. If the world is to meet the Paris Accords goals for greenhousegas-emissions, computing must reduce its direct emissions.

Equally daunting is the rapid growth of waste from computing electronics, notably consumer products, smartphones, and the plethora of "smart devices" collectively termed the "Internet of Things." In 2016, e-

a Of course, I do not mean to imply that there have been no efforts to date- much to the contrary. But, rather to call for renewed and universal engagement on this agenda. waste reached 44.7 million metric tons per year, comparable to the size of the nine Pyramids at Giza, or 1.23 million 18-wheel trucks full of trash. This is an $8 \%$ increase from only two years earlier. ${ }^{7}$ Of this massive quantity, only a fraction is collected and recycled, with the largest fraction simply dumped into landfills or incinerated. Any claims that computing is "good" for the environment, must reckon with this waste problem.

Some computing professionals believe that Moore's Law or Dennard scaling mitigates these problems. Far from it, they actually exacerbate it! Efficiency is not a solution, as $19^{\text {th }}$-century British Economist William Stanley Jevons noted in 1865, "efficiency increases consumption," a rule widely known as Jevon's Paradox. ${ }^{4}$

Carbon offsets are constructive, but not enough. As regions undertake ambitious 100\% renewable fraction goals-San Diego (2035), California (2045), European Union (entire economy 2045)—offsets are of decreasing benefit. Real solutions must achieve di-

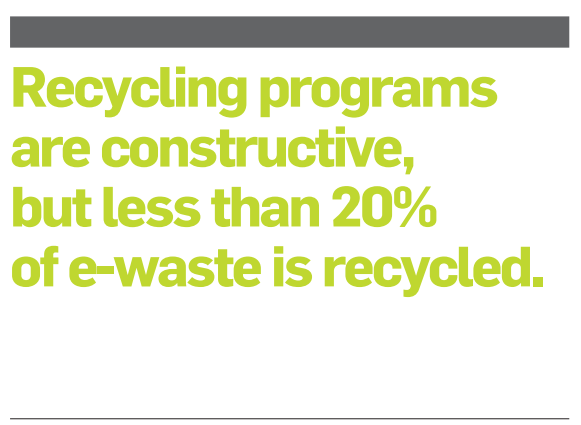

rect matching and supply following. ${ }^{2,8}$ Recycling programs are constructive, but less than $20 \%$ of e-waste is recycled-it is just not economic. Innovative approaches to capture or render benign e-waste are a critical need.

Computing technologies and systems must be designed and shaped for lower carbon and environmental impact. Here is a call to action to the computing community: Let's adopt goals equally ambitious to those of the climate community.

Let's create technologies and systems that in their manufacture, construction, and operation approach the goal of $100 \%$ carbon-free and neutral environmental impact!

\section{Andrew A. Chien, EDITOR-IN-CHIEF}

Andrew A. Chien is the William Eckhardt Distinguished Service Professor in the Department of Computer Science at the University of Chicago, Director of the CERES Center for Unstoppable Computing, and a Senior Scientist at Argonne National Laboratory.

\section{References}

1. Dreyfuss, E. How Google keeps its power hungry operations carbon neutral. Wired (Dec. 1, 2018)

2. Google White Paper. Moving toward $24 \times 7$ CarbonFree Energy at Google Data Centers: Progress and Insights.

3. Greenpeace. Clicking Clean: Who is winning the race to build a green Internet?

4. Jevon, W. The Coal Question. Macmillan, 1865

5. Jones, N. How to stop data centres from gobbling up the world's electricity. Nature (Sept. 12, 2018)

6. Shehabi, A. et al., United States Data Center Energy Usage Report. LBNL, June 2016

7. United Nations University. The Global E-waste Monitor 2017 (Dec. 2017)

8. Yang, F. and Chien, A.A. ZCCloud: Exploring Wasted Green Power for High-Performance Computing, IPDPS, May 2016. 